\title{
AS RAÍZES E O FUTURO DO "HOMEM CORDIAL" SEGUNDO SÉRGIO BUARQUE DE HOLANDA
}

\author{
Ricardo Luiz de Sonza*
}

Publicado em 1936, Raízes do Brasil é, niti- metodológico, a influência de Max Weber é nítida, damente, uma obra de transição. Busca explicar o menos pelas inúmeras referências ao sociólogo aleBrasil de forma ensaística, como Gilberto Freyre, mão e mais pela própria estrutura da argumentaEuclides da Cunha, Sílvio Romero e outros o fize- ção" (Saes, 2000, p. 4-13). De fato, o método utiliram, mas, ao mesmo tempo, já se nota a presença zado por Sérgio Buarque é genético e weberiano: de parâmetros científicos que, em Freyre, ainda busca a gênese, as raízes do processo histórico a estão perdendo espaço para a intuição. Dessa for- ser analisado e intenta enquadrar esse processo ma, na longa transição entre o ensaísmo e a adoção em uma tipologia weberiana, de cuja utilização ele de padrões científicos, que caracteriza os anos 30, é pioneiro entre nós.

o livro representa um inegável avanço.

Esse processo histórico gerou, por sua vez,

As regularidades apontadas por Buarque no processo de formação nacional não tendem a adquirir caráter definitivo. São construções teóricas passíveis de reformulação pelo autor, como de fato ocorreu, ao contrário da obra de Gilberto Freyre, por exemplo, na qual os conceitos básicos formulados ainda nos anos 20 permanecem inalterados em plenos anos 80 .

Saes acentua, a respeito da influência weberiana sobre o autor, que: "Do ponto de vista

* Professor-Doutor da Fundação Educacional Monsenhor Messias - UNIFEMM. Centro Universitário de Sete Lagoas. Av. Mal. Castelo Branco, 2765. Santo Antonio - Sete Lagoas-MG - Brasil. Cep: 35.701-242 riclsouza@uol.com.br uma identidade específica, cujas raízes estiveram presentes na sua evolução e foram por ele, ao mesmo tempo, determinadas: são as raízes do Brasil. E fica, então, a pergunta: "Por que raízes? Sérgio Buarque faz apelo a uma metáfora orgânica: se há raízes, há solo, plantas, árvores, frutos. Tudo o que frutificou aqui - e o verbo é utilizado inúmeras vezes, ao longo do livro - alimentou-se dessa seiva primeira, o impulso trazido pelo colonizador" (Veloso; Madeira, 1999, p. 166). A busca dessas raízes implica a busca da identidade nacional, a busca de uma chave para sua decifração.

Trata-se de uma identidade pensada a partir de dualidades. Gera-se, entre o trabalhador e o 
aventureiro, por exemplo, uma dicotomia salientada por Leenhardt, a partir da qual "o aventureiro ibérico não saberia compreender, e ainda menos partilhar, o comportamento social e o comportamento econômico do trabalhador, figura característica do mundo sociopolítico do norte europeu" (Leenhardt, 2005, p. 96). E ainda, como acentua Antônio Cândido em sua introdução clássica a Raízes do Brasil, Buarque trabalha com dualidades, com pares, como "trabalho e aventura; método e capricho; rural e urbano; burocracia e caudilhismo; norma impessoal e impulso afetivo" (Cândido, 1996, p. 13).

Nessas dualidades, fica patente a distinção efetuada por Max Weber entre os diferentes tipos de legitimação, com o trabalho, o método, o urbano, a burocracia e a norma impessoal, situando-se no campo dominado pelo que ele chama de "domínio em virtude da legalidade, em virtude da fé na validade do estatuto legal e da competência funcional, baseada em regras racionalmente criadas" e com os pólos opostos de cada par situando-se no terreno dos tipos de autoridade tradicional e carismática (Weber, 1974, p. 99). São esses tipos de autoridade, segundo Buarque (embora ele não as mencione segundo a tipologia weberiana), que têm predominado no Brasil, e é a utilização dessa dualidade e a constatação desse predomínio que irão nortear o pensamento do autor.

Nesse contexto ainda, e seguindo a terminologia weberiana, a autoridade estatal não tem como manter o monopólio legítimo da autoridade, que se espraia pela sociedade. A cordialidade brasileira não exclui a violência: pelo contrário, o Homem Cordial é um homem dado a atitudes extremas, capaz de agir com extrema violência. Extrema porque se trata de uma violência que atua fora dos meios legais de coerção, e extrema porque é a expressão de um comportamento incapaz de moldar-se a padrões legais e à ordem pública. A tal ordem o Homem Cordial contrapõe a lógica da esfera privada e de seus códigos particulares, que são os códigos dessa esfera. É essa violência - que não é a violência weberiana, monopolizada pelo Estado, e, sim, a violência privada, sancionada por

códigos particulares - que leva o autor a contestar a tese de ser a história do Brasil uma história incruenta, o que é visto por ele, aliás, como um conceito historicamente insustentável:

\begin{abstract}
De todas as histórias nacionais pode ser dito que são cruentas e a do Brasil naturalmente não forma exceção. E pretender que o tenha sido - a do Brasil - em menor ou maior grau do que a dos outros povos já é matéria dependente de critérios de mensuração e naturalmente de termos de comparação, que até o momento ainda não se descobriram (Holanda, 1996a, p. 300).
\end{abstract}

O Homem Cordial é definido por Greco como protótipo do não-cidadão, pelo fato de o seu perfil não se adequar à esfera pública, simbolizando, ainda, uma sociedade que prefere obedecer a assumir responsabilidades (Greco, 2001, p.74). E não se adequa à modernidade, ainda, devido a uma característica ressaltada por Buarque, que menciona o "horror às distâncias que parece constituir, ao menos até agora, o traço mais específico do caráter brasileiro" (Holanda, 1996b, p. 149).

O prestígio que o romantismo ganhou no Brasil derivou, segundo Sérgio Buarque, de um personalismo inato:

Se o romantismo adaptou-se tão bem ao nosso gênio nacional, a ponto de quase se poder dizer nunca a nossa poesia pareceu tão legitimamente nossa como sob a sua influência, deve-se ao fato de persistir, aqui como em Portugal, o velho prestígio das formas simples e espontâneas, dos sentimentos pessoais, a despeito das contorções e disciplinas seculares do cultismo e do classicismo (Holanda, 1996a, p.365).

Isso decorre do fato de recusarmos o formalismo e buscarmos fundamentar nossas relações em uma intimidade que prioriza o contato pessoal, em detrimento da regulamentação jurídica, que deve, segundo Weber, definir as relações burocráticas, excludentes em relação a qualquer determinação pessoal. No Brasil, ao contrário, "cada indivíduo afirma-se ante os seus semelhantes indiferentes à lei geral, onde esta lei contrarie suas afinidades emotivas, e atento apenas ao que o distingue dos demais, do resto do mundo" (Holanda, 1996b, p. 155). O brasileiro, segundo 
Buarque, é antiweberiano por excelência e, por isso, Cândido ressalta, no já mencionado ensaio, o que chama de inadequação visceral desse homem cordial às "relações impessoais que decorrem da posição e da função do indivíduo, e não da sua marca pessoal e familiar, das afinidades nascidas na intimidade dos grupos primários” (Candido, 1996, p. 17). E a análise de Cândido é reforçada pela conclusão de Souza:

Uma leitura atenta da caracterologia do homem cordial descobre que ele é, ponto por ponto, o inverso perfeito do protestante ascético como é descrito por Max Weber...Como resultado - daí a caracterologia do homem cordial ser a essência do livro -, não temos aqui nem mercado capitalista moderno nem democracia digna deste nome. (Souza, 1999a, p.79-80).

A continuidade da tradição ibérica gera um tempo que, ao invés de se renovar, produz a reafirmação secular dos traços de significado (Pesavento, 2005, p. 59). E tal continuidade gera uma questão igualmente salientada por Pesavento: "O brasileiro, para salvar seu país das garras do passado, precisaria ser um outro? No mínimo, precisaria matar seu passado, aniquilar seu perfil identitário" (2005, p. 70). Por isso, uma preocupação central da obra de Buarque é descobrir as raízes do Homem Cordial, traçar sua genealogia e refletir sobre sua ação determinante em relação a diversos aspectos da história brasileira. Como, por exemplo, o que ele define como o caráter epidérmico das rebeliões que antecederam e sucederam a Independência, o qual possui, na perspectiva do autor, origens ao mesmo tempo políticas e identitárias: "Não é em suma o mesmo paternalismo, de raízes coloniais e barrocas, que forma, ainda hoje, abertamente ou não, o núcleo de quase toda atividade política no Brasil?" (Holanda, 2004, p. 93).

Ele faz isso, igualmente, em artigo publicado em 1947, quando acentua: "a repulsa firme a todas as modalidades de racionalização e, por conseguinte, de despersonalização, tem sido, até aos nossos dias, um dos traços constantes dos povos de raízes ibéricas" (2004, p. 51). E ressalta, ainda, alguns dos traços básicos do ethos econômico de tais povos:
O que os distingue em primeiro lugar é, isso sim, o uso que fazem de preferência da riqueza acumulada, destinando-a a garantir-lhes antes a ostentação ou o luxo que o próprio conforto. E, além disso, uma incapacidade, que se diria congênita, de conceber qualquer forma de ordenaçã̃o impessoal e mecânica prevalecendo sobre os vínculos de caráter orgânico e comunal, como são os que se fundam no parentesco, na vizinhança e na comunidade (p. 56).

Partindo de tais pressupostos, ele coloca nesses termos a questão da incompatibilidade entre a mentalidade dos povos ibéricos e o capitalismo: "como explicar satisfatoriamente a constante resistência oferecida pelos mesmos povos a esse produto natural dos novos tempos, e a mentalidade capitalista?" Coloca como critério, então, o conhecimento apenas superficial que tais povos possuíam acerca das relações sociais características do novo sistema. E conclui: "De onde, entre portugueses e espanhóis, um igualitarismo fundamental, posto que nem sempre muito ostensivo, e que teve exemplo, talvez, no mundo muçulmano, mas que o resto da Europa cristã ignorou, ao menos até a aurora dos tempos modernos" (Holanda, 2004, p. 49).

A condenação do passado colonial não é, porém, absoluta, à maneira de um Manoel Bomfim, o que leva Finnazi-Agró a mencionar a existência, em Caminhos e fronteiras, de uma rememoração nostálgica de um passado ainda caracterizado por relações complexas entre culturas diferentes e pela acolhida do discurso do outro. E a concluir: "Hoje, aquilo que fica são apenas elementos esparsos e esgarçados de um tecido que apenas a sabedoria e o amor orgânico do estudioso conseguem retecer num desenho orgânico" (Finazzi-Agró, 2005, p. 153). E há, na avaliação de Sérgio Buarque, uma ambigüidade captada com precisão por Silva: “Se o Homem Cordial representa, de certa forma, nosso não-lugar na modernidade, ele constitui ainda um híbrido entre a tradição e a modernidade. Seus rompantes modernos, apesar de sufocados pelos traços tradicionais, são latentes, o que evidencia um sujeito singular, criatura nacional" (Silva, 2005, p. 130). Mas, apesar da constatação de tal singularidade, Paoli acentua, também de forma precisa, a conexão efetuada por Sérgio Buarque, em Raízes 
do Brasil, entre cordialidade e o que a autora chama de "desrealização republicana da modernidade." (Paoli, 2003, p. 167). E a cordialidade brasileira é, por fim, enfaticamente definida por Sérgio Buarque como nociva ao indispensável processo de organização política nacional:

Em sociedade de origens tão nitidamente personalistas como a nossa, é compreensível que os simples vínculos de pessoa a pessoa, independentes e até exclusivos de qualquer tendência para a cooperação autêntica entre os seus componentes, tendo em vista um fim exterior a eles, foram sempre os mais decisivos. De onde, com certeza, a vitalidade, entre nós, de certas forças afetivas e tumultuosas, em prejuízo das qualidades de disciplina e método, que parecem melhor convir a um povo em vias de se organizar politicamente (Holanda, 2004, p.81).

Sérgio Buarque pensou em oposição a correntes de pensamento que utilizaram, igualmente, a influência colonial como elemento decisivo para a compreensão do Brasil contemporâneo. E Oliveira Viana é, nesse sentido, o nome mais evidente a ser lembrado. Ele trabalhou, segundo Canedo, com o mesmo conjunto de elementos de Viana, desenvolvendo o conceito de cordialidade, derivado, por sua vez, da "cultura da personalidade ibérica” (Canedo, 1994, p. 90). Mas Buarque afirma ter ressaltado, em Raízes do Brasil, a herança indígena e mameluca, em deliberada oposição às concepções arianistas de Oliveira Viana (Graham, 1982, p. 13). E a relação entre colonizadores e indígenas, no período das monções, é, na descrição de Buarque, ao contrário do que ocorre na análise histórica de Viana, longe de ser idílica: "É o confronto de duas humanidades tão diversas, tão heterogêneas, tão verdadeiramente ignorantes, agora sim, uma da outra, que não deixa de impor-se entre elas uma intolerância mortal" (Holanda, 1986, p. 59). A oposição entre os autores torna-se, assim, nítida.

Já em relação a Freyre, delineia-se um conjunto complexo de contrastes e aproximações. Tanto Gilberto Freyre quanto Sérgio Buarque trabalham a partir de dualidades, mas, enquanto as dualidades de Freyre caminham no sentido da adaptação, as dualidades de Buarque estão em constante e instá-

vel tensão (Costa, 1992, p. 237). Nesse sentido, Monteiro aponta uma distinção fundamental entre ambos os autores: Freyre registra um equilíbrio de antagonismos entre poder público e privado no período colonial, "já Sérgio Buarque viu ali sobretudo o conflito, ou uma invasão totalmente indevida" (Monteiro, 1999, p. 179), com o sistema patriarcal servindo como obstáculo à expansão da atividade política. Como conseqüência, o espaço público passa a pautar-se por regras próprias da esfera privada e, dessa forma, ainda segundo Monteiro, “... é o relacionamento com todos que deve dar-se numa conduta tipicamente cordial, sobre bases concretas e personalizadas, imediatizadas, de modo a reconhecer, pessoal e diretamente, cada qual com quem está se mantendo algum tipo de ligação" (p. 228).

Não há lugar, nesse contexto, para o indivíduo abstrato e neutro: ele é sufocado por uma teia de relações que é tecida sob o signo da cordialidade, mas sacramenta a hierarquia e a desigualdade. Concluindo, ainda com Monteiro, “... a cordialidade não constituía, evidentemente, uma base satisfatória para a ereção de um Estado democrático, que, ao contrário dos valores cordiais, pressupunha uma radical despersonalização" (p. 244).

Buarque tenta identificar as raízes do Brasil, mas é uma tentativa que se configura como contraditória, na medida em que o brasileiro é caracterizado como portador de uma identidade sem raízes: "somos ainda hoje uns desterrados em nossa terra" (Holanda, 1996b, p. 31). Esse desterro se liga ao que ele define como a predominância do caráter de exploração comercial da colonização portuguesa, mais preocupada em explorar a terra, ainda que de forma predatória, do que em estabelecer-se nela de forma consistente (Holanda, 1996b, p. 98).

Tal tentativa liga-se, por sua vez, à questão: qual é, para Sérgio Buarque, o sentido da colonização (para utilizarmos uma expressão cara a Caio Prado)? "O princípio que, desde os tempos mais remotos da colonização, norteara a criação da riqueza no país, não cessou de valer um só momento para a produção agrária. Todos queriam extrair do solo excessivos benefícios sem grandes sacrifícios" (Holanda, 2004, p. 74). E, a partir de tal de- 
finição, ele faz a crítica irônica dos que acreditam na ação sábia e orientadora da coroa no processo de povoamento das terras brasileiras, dos que partilham "a crença numa singular habilidade e astúcia da política lusitana, que chegaria mesmo a ser seu traço distintivo em confronto com a castelhana" (Holanda, 1986b, p. 91). Portugal, enfim, não levou em mínima conta a proposta, o projeto de construir uma civilização, e Vainfas acentua, a existência, em Visão do Paraíso, da noção de um paraíso ausente, "tragado pelos interesses imediatos de uma colonização predatória e pouco ligada a motivações propriamente civilizacionais." (Vainfas, 2002, p. 42).

Como o brasileiro não criou raízes, não buscou criar uma obra duradoura, visando, pelo contrário, apenas a explorar os lucros de quem busca criar essa obra por ele. Nasce daí a prioridade dada a "uma digna ociosidade", em detrimento da "luta insana pelo pão de cada dia” (Holanda, 1996b, p. 38) e, aqui, continuamos antiweberianos: situamonos nas antípodas de qualquer ética protestante (Souza, 1999b, p. 59). Não somos descendentes de nórdicos protestantes, somos descendentes de Portugal: "de lá nos veio a forma atual de nossa cultura; o resto foi matéria que se sujeitou mal ou bem a essa forma" (Holanda, 1996, p. 40). Exemplo desse fundamento, digamos, genético da identidade nacional é, para Buarque, o fracasso de Mauá, que atesta a impossibilidade de adoção, no Brasil, do espírito do capitalismo e que funciona como "indício eloqüente da radical incompatibilidade entre as formas de vida copiadas de nações socialmente mais avançadas, de um lado, e o patriarcalismo e personalismo fixados entre nós por uma tradição de origens seculares" (Holanda, 1996b, p. 79).

Essa predominância da influência lusitana não significa a inexistência de adaptações ao meio ou de outras influências e adaptações, que ocorreram em termos de alimentação, moradia e modo de produção (p. 47). E o escravo exerceu sua influência, com a associação entre patrimonialismo e escravidão tendo levado o autor, segundo Aguiar, a aplicar o conceito com relação ao Brasil e a destacar a abolição da escravidão como um dos princi- pais fatores explicativos do processo de mudança na sociedade brasileira (Aguiar, 2000, p. 316).

Não foi, contudo, uma influência que contestasse o personalismo nacional - antes o reforçou-, na medida em que "penetrava sinuosamente o recesso doméstico, agindo como dissolvente de qualquer idéia de separação de castas ou de raças, de qualquer disciplina fundada em tal separação" (Holanda, 1996b, p. 55). Mesmo o escravismo, portanto, recusou qualquer impessoalidade mais rígida, e Buarque insiste, como Freyre, na ausência de orgulho racial por parte do colonizador português. E ele menciona, em praticamente todos seus textos, segundo Wegner, a plasticidade da colonização portuguesa (Wegner, 2000, p. 124), termo também recorrente na obra de Freyre, utilizado como elemento explicativo para a miscigenação imperante em terras brasileiras. Nesse escravismo, ao contrário de qualquer mentalidade mais especificamente voltada para a produção racional, o que imperou foi a "moral das senzalas", que ele define como "contemporizadora enarcotizante de qualquer energia realmente produtiva” (Holanda, 1996b, p. 62). Foi a cordialidade lusitana - raiz da tradição ibérica na qual fomos criados, do iberismo de fundamental importância em Buarque - que gerou a plasticidade da colonização portuguesa, tão referida por Freyre. Permitiu ao português misturar-se sem maiores restrições ao negro e ao índio, criando uma cultura ambivalente, como assinala Gomes, originalmente branca e européia, mas vinculada a tradições negras e índias. E conclui a autora: "Este o dilema e também a riqueza de nossos impasses nacionalistas, manifestem-se eles em propostas literárias, políticas ou sociais” (Gomes, 1990, p. 19).

Falta, por outro lado, à colonização inglesa, essa plasticidade que caracteriza o processo colonial português. Por outro lado, o espírito empreendedor e empresarial, a capacidade de trabalho e a coesão social são características que faltam a esse processo e definem a colonização levada adiante pelos britânicos (Morse, 1996, p. 77). Não é que falte capacidade empreendedora ao português, mas ela se exercita de forma predatória, a partir da con- 
quista, da exploração e da destruição, gerando ciclos econômicos que se esgotam rapidamente e nada deixam para trás, a não ser ruínas. Mais ainda: o colonizador de origem inglesa era movido pelo "afã de construir", enquanto o português deixou-se atrair "pela esperança de achar em suas conquistas um paraíso feito de riqueza mundana $\mathrm{e}$ beatitude celeste, que a eles se ofereceriam sem reclamar labor muito maior mas sim como um dom gratuito" (Holanda, 1977, xviii, 360p.). Trabalhando a dicotomia entre as diferentes colonizações a partir da dualidade proposta por Buarque, Lippi de Oliveira ressalta as diferentes representações da natureza que fundamentam cada processo:

A representação puritana da natureza contrasta com o que foi apresentado... Para os puritanos, não cabia nem conquistar nem descobrir a natureza, mas o conhecimento e a domesticação, tarefas que requeriam muito trabalho e muita "ação de graça" (matéria-prima do rito nacional mais importante nos Estados Unidos: o dia de Ação de Graças). (Oliveira, 2000, p. 41).

A plasticidade portuguesa é exemplificada por Buarque a partir do aprendizado de técnicas de caminhada e de sinalização mato adentro. $\mathrm{O}$ português adapta-se às técnicas indígenas e as utiliza com inteiro sucesso e sem nenhum prurido. $\mathrm{E}$ ele conclui: "E estavam certamente nessa incorporação necessária de numerosos traços da vida do gentio, enquanto não fosse possível uma comunidade civil e bem composta, segundo os moldes europeus" (Holanda, 1975, p. 17). Nesse sentido, Jessé Souza aponta ainda outra interpretação para a plasticidade portuguesa, na perspectiva de Buarque: "A plasticidade é uma espécie de virtude dos fracos, espelhando a predisposição para o ajuste e o compromisso, em vez da sobranceira imposição unilateral da vontade também típica dos calvinistas. É essa circunstância que faz Buarque afirmar que, neste terreno particular, a fraqueza lusitana foi sua força” (Souza, 2000, p. 164).

Onde Freyre faz o elogio da plasticidade erigindo-a em fundamento da democracia racial, portanto-, Buarque também credita a ela a capacidade de adaptação do português ao trópico e a construção de uma nação tropical. Até aí, ele e Freyre caminham juntos. Mas, aqui, já é indispensável atentarmos para um fator mencionado por Souza que estabelece uma clivagem entre os autores: "O fato é que essas qualidades, as quais foram tão importantes na criação de uma grande nação nos trópicos, como a plasticidade, a capacidade de acomodação e o compromisso com o gentio e com o meio físico, serem as mesmas vistas, agora, como obstáculo à criação de uma grande nação moderna" (Souza, 1999c, p. 35). E a clivagem a ser feita em relação ao futuro reflete-se na avaliação do passado e de sua herança. Se Freyre reitera a necessidade de conservarmos a tradição lusitana como uma maneira a única realmente válida - de preservarmos a identidade nacional, Buarque aponta para a direção oposta. Para ele, "o 'mundo que o português criou' não interessa ao Brasil, que deve criar o seu próprio mundo e que, para fazê-lo, terá de romper com o seu passado português” (Reis, 1999, p. 122).

$$
* * *
$$

Dias define como preocupação intelectual decisiva da obra do autor "a resistência pertinaz e sistemática contra critérios abstratos, lógicos, por conseguinte, a-históricos e desvirtuadores do processo histórico, não raro a serviço de entidades metafísicas ou de interesses específicos de classe ou do Estado" (Dias, 1985, p. 13). A tais esquemas, Sérgio Buarque opõe a empatia como método analítico, com a compreensão histórica nascendo necessariamente, segundo ele, de uma relação empática entre o historiador e seu objeto de estudo: "A evocação de tempos idos reclama, sem dúvida, um sentimento vivo daqueles tempos, bastante vivo para criar entre o observador e o observado, entre o historiador e o objeto da história, essa corrente de simpatia que há de animar toda verdadeira compreensão" (Holanda, 2004, p. 102). E Antônio Cândido acentua, nesse sentido, o caráter radical de Raízes do Brasil. Esse é, segundo ele, o único livro “meio alemão" de Sérgio Buarque, na medida em que ele se vale do recurso à intuição e à empatia, característico de autores alemães contemporâneos, para definir a existência histórica de 
tipos, em um esforço também marcadamente alemão. Mas faz isso sem cair no conservadorismo que costuma acompanhar tal esforço. E Cândido conclui:

A “empatia”, o entendimento global que descarta o pormenor vivo, a "visão orgânica", a confiança em certa mística dos "tipos", tudo isso foi despojado por ele de qualquer traço de irracionalidade, moído pela sua maneira peculiar, e desaguou numa interpretação aberta, extremamente crítica e radical (Cândido, 1989, p. 124).

Cândido define Raízes do Brasil como um momento alto do pensamento radical brasileiro, na medida em que rompia com a solução liberal, que atribuía às elites a tarefa de conduzir a nação e tutelar o povo, e passava a atribuir a esse mesmo povo a "capacidade de iniciativa e criatividade política". E, situando historicamente a obra, afirma: "O livro saiu pouco depois do esmagamento da Aliança Nacional Libertadora e é voltado claramente contra os autoritarismos, tanto os herdados da velha estrutura oligárquica, quanto os surgidos da conjuntura contemporânea, como o integralismo" (Cândido, 1988, p. 65).

Buarque seria, em síntese, um crítico radical do conservadorismo, tal como Konder também o descreve:

A reação de Sérgio contra esse ponto de vista conservador, que induzia o observador à passividade, consistiu em reexaminar de um ângulo energicamente crítico o panorama da nossa história, para enxergar as manifestações de movimentos subterrâneos em áreas culturais nas quais se negava a existência de qualquer movimento significativo (Konder, 1991, p. 63).

A crítica de Buarque ao nacionalismo verde-amarelista, que desaguaria, afinal, no integralismo, caminha, de fato, nesse sentido: ele denuncia, ali, um processo de remodelação conservadora e uma tentativa de manutenção de padrões culturais de onde nascem os bacharéis e caudilhos (Prado, 1983, p. 93). Padrões constituídos, em síntese, a partir da tradição ibérica; um conservadorismo que encontra em Buarque, de fato, um crítico e um oponente

Retomando, contudo, a tarefa de situar his- toricamente Raízes do Brasil, é preciso pensá-lo em um momento de crise do ideário liberal do qual a Revolução de Trinta foi, ao mesmo tempo, conseqüência e tentativa de resolução em um momento no qual se perguntava: "Como conciliar essa crise do ideário liberal, generalizada, aliás, no mundo inteiro no decênio de 30, com aquilo que o historiador considerava a 'essência íntima' do caráter lusobrasileiro, isto é, o culto do indivíduo e a tibieza de tudo quanto significasse ordem ou obediência a um princípio impessoal” (Bosi, 1988, p. 153)?

Em um momento, também, de reiteradas constatações da incompatibilidade entre esse ideário e as características orgânicas do brasileiro, de suas raízes históricas e de sua identidade, de constatações que buscavam criar uma fórmula política que se adequasse ao individualismo, às tendências anárquicas e à incapacidade de criar associações políticas e sociais estáveis, Raízes do Brasil é uma busca entre tantas outras formuladas no período, e como tal deve ser analisada.

Por outro lado, e buscando defender Freyre de seus supostos detratores, sempre dispostos a reverenciar Sérgio Buarque em detrimento da obra freyreana, segundo Chacon, este situa em Carl Schmitt a fonte metodológica para a criação do homem cordial, e lembra: "Já em 18 de junho de 1933, atente-se bem para a data, no artigo ‘O Estado totalitário’ para a Folha da Manhã de São Paulo, Sérgio Buarque era o primeiro a divulgar sua obra no Brasil, chamando-o ali, duas vezes, 'o sábio professor da Universidade de Bonn”” (Chacon, 1993, p. 298).

A solução proposta por Buarque, se não é ela mesma autoritária, leva, contudo, ao autoritarismo. Segundo Scwharcz, Sérgio Buarque vê como possível e desejável a "emergência de instâncias de representação que se sobrepusesse às persistentes estruturas íntimas" (Scwharcz, 1998, p. 238), e instâncias de representação - evidentemente políticas - significam, nesse contexto, a preponderância do poder racional-legal, tal como definido por Weber. Desejável, certamente, mas possível? Improvável seria a expressão correta.

Já Avelino Filho aponta a abertura de 
Buarque para uma saída autoritária, mas a relativiza, afirmando que "seria difícil concretizar este tipo de 'autoritarismo iluminado', cujos dirigentes não poderiam estar ligados à cultura cordial” (Avelino Filho, 1990, p. 12). Acontece que essa dificuldade é ressaltada pelo autor, não por Buarque.

A ordem social brasileira funda-se, como vimos, antes em personalismos e preferências pessoais que em uma neutralidade jurídica indispensável para a adoção de qualquer regime democrático. Para Buarque:

Todo afeto entre os homens funda-se forçosamente em preferências. Amar alguém é amá-lo mais do que a outros. Há aqui uma unilateralidade que entra em franca oposição com o ponto de vista jurídico e neutro em que se baseia o liberalismo. A benevolência democrática é comparável nisto à polidez, resulta de um comportamento social que procura orientar-se pelo equilíbrio dos egoísmos. O ideal humanitário que na melhor das hipóteses ela predica é paradoxalmente impessoal; sustenta-se na idéia de que o maior grau de amor está por força no amor ao maior número de homens, subordinando, assim, a qualidade à quantidade (Holanda, 1996b, p. 185).

Nada disso, por imaterial e impessoal, existe no Brasil, e é a própria “idéia de uma espécie de entidade imaterial e impessoal, pairando sobre os indivíduos e presidindo os seus destinos" (Holanda, 1996b, p. 183) que é, para o brasileiro, segundo ele, dificilmente inteligível. Ora, tal identidade, baseada em ideais humanitários, é claramente identificada com o próprio regime democrático ao qual somos, ao fim e ao cabo, intrinsecamente avessos. Predominam, no Brasil, elementos anárquicos incapazes de se associarem permanentemente em forças ativas (p. 33). Com isso, anarquia e obediência surgem como princípios complementares. Nas palavras do autor:

À autarquia do indivíduo, à exaltação extrema da personalidade, paixão fundamental que não tolera compromissos, só pode haver uma alternativa: a renúncia a essa mesma personalidade em vista de um bem maior. Por isso mesmo que rara e difícil, a obediência aparece algumas vezes, para os povos ibéricos, como virtude suprema entre todas (p. 39).

É a obediência a um poder autoritário, portanto, e não o cumprimento de regras impessoais, baseadas em princípios abstratos, o que melhor se adapta à identidade nacional. Nesse contexto, qualquer organização política é necessariamente precária, e precária justamente por depender de uma “cooperação autêntica entre os indivíduos”, exatamente onde os vínculos pessoais são mais fortes. Em artigo publicado em 1941, em Cultura Política, principal órgão de veiculação da ideologia estadonovista, lemos:

Reduzida a uma fórmula esquemática o nosso ancestralismo sociológico, nela encontraríamos o seguinte quadro de expressão:

Fatores democráticos representativos $=0$

Fatores propícios à investidura pessoal $=100 \%$ (Arraes, 1983, p. 238).

Nessa tradução sumária do esquema proposto por Buarque, fica claro até que ponto ele pôde ser aproveitado pelo pensamento autoritário e nele se enquadrou. Trata-se de um esquema retomado por ideólogos do autoritarismo, que o utilizariam para defender a centralização política promovida por Getúlio. Azevedo Amaral, por exemplo, afirma:

Na nossa história colonial as idéias de unidade e de autonomia regional contrapõem-se, respectivamente, representadas pelo município e pela província. A província correspondia preponderantemente aos interesses comerciais e associava-se à mentalidade citadina da burguesia mercantil das cidades... E além dessa determinante econômica do regionalismo burguês, reforçava o próprio espírito lusitano, porque a província sendo um instrumento de fragmentação moral da nacionalidade nascente, enquadrava-se no nos planos do governo metropolitano de impedir que os Brasis se tornassem um dia um grande Brasil unido e independente (Amaral, 1941, p. 38).

A aproximação entre Amaral e Buarque não é fortuita, uma vez que ambos partem de um pressuposto semelhante: faltou e falta organicidade à sociedade brasileira, e essa falta torna difícil ao país conceber-se como nacionalidade, o que gera a pergunta: como criar uma nacionalidade brasileira? Buscando responder a essa pergunta, ambos situam o problema no predomínio de interesses provinciais e particulares sobre um projeto nacional ainda a ser articulado (Baggio, 1991, p. 125-129).

Referindo-se à Colônia, Buarque afirma que 
“as agregações e relações pessoais, embora por vezes precárias, e, de outro lado, as lutas entre facções, entre famílias, faziam dela um todo incoerente e amorfo" (Holanda, 1996b, p. 61). É nesse todo, porém, que ainda predomina o Homem Cordial, avesso a qualquer princípio abstrato que ainda prevalece no país e faz indispensável a adoção de um regime autoritário capaz de ordená-lo. É por isso que a "democracia no Brasil foi sempre um lamentável mal-entendido” (p. 160), e é por isso também que

O Estado, entre nós, não precisa e não deve ser despótico - despotismo condiz mal com a doçura de nosso gênio -, mas necessita de pujança e compostura, de grandeza e solicitude, ao mesmo tempo, se quiser adquirir alguma força e também essa respeitabilidade que os nossos pais ibéricos nos ensinaram a considerar a virtude suprema entre todas. Ele ainda pode conquistar por esse meio uma força verdadeiramente assombrosa em todos os departamentos da vida nacional (p. 176).

É a diferença, porém, entre um Estado despótico e um Estado pujante que permanece perigosamente fluida.

Ao mesmo tempo, ainda que essa diferença seja fluida, o Estado, tal como concebido por Sérgio Buarque, é estático (Fernandes, 1979, p.96), na medida em que o autor toma como ponto de partida uma identidade (a do Homem Cordial) e não uma realidade social específica. A superação do Homem Cordial só poderá ser efetuada, finalmente, através da modernização da sociedade brasileira, uma vez que ela pressupõe a urbanização dessa sociedade e a superação de seu personalismo e aristocratismo (Leite, 1976, p. 291). É a partir da racionalização dessa sociedade (racionalização a ser feita, em linhas gerais, em moldes weberianos) que conseguiremos superar a tendência nacional ao autoritarismo. Segundo Sérgio Buarque, weberiano, o Brasil será democrático.

É preciso não tomar, porém, o conceito de cordialidade, em Raízes do Brasil, como uma diretriz imutável na evolução da obra de Buarque. Já em 1948, como lembra Moreira, Buarque, em polêmica como Cassiano Ricardo, já denunciava a irrelevância do conceito e, em Raízes do Brasil, ele se recusava a afiançar, sem apelo, a incompatibilidade absoluta entre o brasileiro e os ideais democráticos (Moreira, 1999, p.206), apesar de, em artigo publicado dois anos depois de decretada sua irrelevância, as características que definem a cordialidade brasileira serem novamente retomadas:

Passamos os brasileiros, bem ou mal, por ser gente de pouco mistério e sem tumultos íntimos: homens de emoção à flor da pele, sociáveis e comunicativos de seu natural. Talvez por isso, os grêmios, as associações, os clubes, que tem geralmente o fito de forçar o trato dos indivíduos, onde este não se faz com espontaneidade, raras vezes deixam de ser entre nós instituições de luxo (Holanda, 1996c, v. 2, p. 158).

A evolução do autor não é, afinal, tão linear quanto se poderia pretender.

Ainda no contexto dessa evolução em relação às linhas mestras de Raízes do Brasil, também a tradição ibérica, descrita na obra a partir de seus componentes anárquicos e resistentes à ação pública, vai perdendo influência. A partir de Monções, o autor descreve esse processo de transição que se dá em contato e sob o impacto do sertão. Segundo Wegner, "nos textos de Holanda percebe-se que, a partir do momento em que entra no sertão o homem ibérico já não seria mais o mesmo. Diante de uma natureza mais forte que ele, foi obrigado a pagar um tributo a ela, adaptando-se. E a sociedade que surgiria daí seria algo nova, não mais totalmente ibérica” (Wegner, 1999, p. 248).

A transição mencionada por Wegner é sintetizada por Buarque em um trecho no qual o sentido da colonização é invertido a partir da reestruturação do processo de povoamento levado a cabo pelas monções, com o apoio da Coroa:

O sistema de povoamento, concebido aqui segundo velha tradição portuguesa, consistia em agremiarem-se numa aparência de vida civil os criminosos e vadios de toda sorte, que então infestavam a capitania. Com a assistência desse pobre material humano, contava a administracão colonial lançar as sementes de um plano soberbo e que teria por objetivo converter o Tietê em uma verdadeira linha estratégica para a ocupação mais efetiva do Oeste e do Sudoeste, ainda mal seguros nas mãos dos portugueses. Tratavase, nem mais nem menos, de corrigir vigorosamente as condições naturais do país, mudando os mais graves obstáculos à penetra- 
ção e à civilização em verdadeiros centros de atração para novos moradores (Holanda, 1989, p. 37).

Permaneceria, contudo, a busca por uma identidade específica a caracterizar a colonização lusitana; permaneceria a busca por uma chave capaz de decifrá-la em sua singularidade. Visão do Paraíso, por exemplo, é um momento crucial dessa busca e, aqui, a chave encontra-se em um pequeno trecho que sintetiza o espírito da obra: "Ainda que fossem muitas vezes sensíveis à atração da fantasia e do milagre, é principalmente o imediato, o cotidiano, que recebem todos os cuidados e atenções desses portugueses do Quinhentos" (Holanda, 1977, p. 101). Daí a disposição peculiar do português perante as terras recém descobertas:

Surgindo com relativo atraso no horizonte das navegacões lusitanas, sem o engodo de tesouros e maravilhas que, bem ou mal, tinham sido causa de tantas outras expedições descobridoras, o Brasil não oferece campo nem mesmo a essas cintilantes associações. Ainda quando vindo por livre vontade, seus antigos povoadores hão de habituar-se nele a uma natureza chã e aparentemente inerte, e aceitá-lo em tudo tal como é, sem a inquieta atração de outros céus ou de um mundo diverso (Holanda, 1977, p. 141)

Eis a matriz identitária que baliza a obra, assim como o homem cordial e a tradição ibérica são as matrizes identitárias de Raízes do Brasil. Nesse sentido, ambos os livros são etapas de um mesmo esforço.

A contradição entre modernidade e formação nacional, a incompatibilidade entre ambas apontada em Raízes do Brasil, tende ainda, segundo Wegner, a ser relativamente abandonada, contudo, em etapas posteriores da obra de Buarque. A partir da segunda metade dos anos quarenta, segundo ele, "surge uma relação entre tradição ibérica e modernidade na qual estas não são incompatíveis de todo, a ponto de se poder até pensar em um otimismo do autor em relação à modernização da sociedade brasileira através de um caminho promissor e rico, ainda que não isento de problemas" (Wegner, 2000, p. 23). Em Raízes do Brasil, são vertentes que se constituem em paralelas e não se encontram (p. 51). Mas, em textos posteriores, que se dedicam a elucidar e a descrever a conquista do oeste pelos paulistas, já é possível falar no surgimento de uma nova mentalidade, diferente e mesmo oposta à descrita em Raízes do Brasil (p. 171).

A obra de Buarque, contudo, é marcada por etapas bem distintas, o que deve ser ressaltado a título de justiça e de conclusão. Referindo-se à obra do autor posterior a Raízes do Brasil, Santos marca a diferença: "Nessas obras, o tom ensaístico adotado em Raízes do Brasil cedia lugar a um estilo mais duro e acadêmico, de trabalho realizado em fontes históricas mais que seculares" (Santos, 1990, p. 54). E, nos anos 70, Buarque mesmo acentua o "caráter plenamente datado" de Raízes do Brasil e se recusa a escrever um ensaio atualizando a obra para uma possível edição francesa. Nas palavras de Bosi, “a vocação de observador e de leitor sereno das fontes venceu o intérprete porventura temerário do primeiro livro" (Bosi, 1988, p. 155). E, se a perspectiva autoritária é clara na etapa de sua trajetória aqui estudada, ela não se manteve e muito menos se acentuou, como no caso, por exemplo, de Gilberto Freyre. Não por acaso, o golpe de 64 encontrou em Freyre um fiel entusiasta de primeira hora e, em Buarque, um decidido opositor.

(Recebido para publicação em março de 2007) (Aceito em julho de 2007)

\section{REFERÊNCIAS}

AGUIAR, Neuma. Patriarcado, sociedade e patrimonialismo. Sociedade \& Estado, Brasília, UNB, v. 15, n. 2, 2000.

AMARAL, Azevedo. Evolução da política imperial. Cultura Política, Rio de Janeiro, n. 2, 1941

ARRAES, Monte. Influência do poder pessoal na ação política do Brasil. Cultura Política. Rio de Janeiro, n. 8, 1941.

AVELINO FILHO, George. Cordialidade e civilidade em Raízes do Brasil. Revista Brasileira de Ciências Sociais, São Paulo, ANPOCS, v. 5, n. 12, 1990.

BAGGIO, Sheila Brandão. A trajetória do liberalismo ao autoritarismo no Brasil. Revista Brasileira de Estudos Políticos. Belo Horizonte, UFMG, n. 73, 1991.

BOSI, Alfredo. Céu, inferno: ensaios de crítica literária e ideológica. São Paulo: Ática, 1988.

CÂNDIDO, Antônio. Sérgio, o radical. In: . Sérgio Buarque de Holanda: vida e obra. São Paulo: Instituto de Estudos Brasileiros, 1988. 
Introdução. In: BARBOSA, Francisco de Assis (Org.). Raízes de Sérgio Buarque de Holanda. Rio de Janeiro: Rocco, 1989.

O significado de Raízes do Brasil. In: HOLANDA, Sérgio Buarque de. Raízes do Brasil. São Paulo: Companhia das Letras, 1996.

CANÊDO, Letícia Bicalho. Caminhos da memória: parentesco e poder. Textos de História, Brasília: UnB, v. 2, n. 3, p. 85-122, 1994.

CHACON, Wamireh. Gilberto Freyre: uma biografia intelectual. São Paulo;Recife: Nacional ; Massangana, 1993.

COSTA, Valeriano Mendes Ferreira. Vertentes democráticas em Gilberto Freyre e Sérgio Buarque. Lua Nova, São Paulo, CEDEC, n. 26, 1992.

DIAS, Maria Odila Leite da Silva. Sérgio Buarque de Holanda, historiador. In: HOLANDA, Sérgio Buarque de. História. São Paulo: Ática, 1985. (Organizado por Maria Maria Odila Leite da Silva Dias)

FERNANDES, Florestan. Mudanças sociais no Brasil. São Paulo: DIFEL, 1979.

FINNAZZI-AGRÓ, Ettore. A trama e o texto: história com figuras. In: PESAVENTO, Sandra Jatahy (Org.). Um historiador nas fronteiras: o Brasil de Sérgio Buarque de Holanda. Belo Horizonte: Ed. UFMG, 2005.

GOMES, Ângela de Castro. A dialética da tradição. Revista Brasileira de Ciências Sociais. São Paulo, ANPOCS, v. 5 , n. 12, 1990.

GRAHAM, Richard. An interview with Sergio Buarque de Holanda. The Hispanic American Historical Review, Durham, Duke University Press, v. 62, n. 1, 1982.

GRECO, Heloísa. O "passado que nos cerca” e a promessa do futuro: considerações sobre a questão da cidadania em Caio Prado Júnior e Sérgio Buarque de Holanda. Fronteiras, Campo Grande, UFMS, v. 5, n. 10, 2001.

HOLANDA, Sérgio Buarque de. Caminhos e fronteiras. Rio de Janeiro: José Olympio, 1975

. Visão do paraíso. São Paulo: Nacional, 1977.

. O Extremo Oeste. São Paulo: Brasiliense, 1986

Monções. São Paulo: Brasiliense, 1989.

Livro dos prefácios. São Paulo: Companhia das Letras, 1996a.

Raízes do Brasil. São Paulo: Companhia das Letras, $1996 \mathrm{~b}$

O espírito e a letra: estudos de crítica literária. São Paulo: Companhia das Letras, 1996c.

. Para uma nova história. São Paulo: Fundação Perseu Abramo, 2004. (Organizado Marcos Costa)

KONDER, Leandro. Intelectuais brasileiros e marxismo. Belo Horizonte: Oficina de Livros, 1991.

LEITE, Dante Moreira. O caráter nacional brasileiro: história de uma ideologia. São Paulo: Nacional, 1976.

LEENHARDT, Jacques. Frente ao presente do passado: as raízes portuguesas do Brasil. In: PESAVENTO, Sandra Jatahy (Org.). Um historiador nas fronteiras: o Brasil de Sérgio Buarque de Holanda. Belo Horizonte: Ed. UFMG, 2005

MAGGIE, Yvonne; REZENDE, Cláudia Barcellos. Raça como retórica: a construção da diferença. Rio de Janeiro: Civilização Brasileira, 2001.

MONTEIRO, Pedro Meira. A queda do aventureiro: aventura, cordialidade e os novos tempos em Raízes do Brasil. Campinas: Ed. UNICAMP, 1999.
MOREIRA, Roberto S. C. Weber e o mal-estar colonial. In: SOUZA, Jessé de (Org.) O malandro e o protestante: a tese weberiana e a singularidade cultural brasileira. Brasília: Ed. Universidade de Brasília, 1999.

MORSE, Richard. The multiverse of latin american identity, c.1920- c.1970. In: BETHEL, Leslie (Org.) Ideas and ideology in twentieth century Latin America. New York: Cambridge University Press, 1996.

OLIVEIRA, Lúcia Lippi. Americanos: representacões da identidade no Brasil e nos Estados Unidos. Belo Horizonte: Ed. UFMG, 2000.

PAOLI, Maria Célia. Movimentos sociais, movimentos republicanos? In: SILVA, Fernando Teixeira da et. al. República, liberalismo, cidadania. Piracicaba-SP: Ed. UNIMEP, 2003.

PESAVENTO, Sandra Jatahy. Cartografias do tempo: palimpsestos na escrita da história. In: (Org.) Um historiador nas fronteiras: o Brasil de Sérgio Buarque de Holanda. Belo Horizonte: Ed. UFMG, 2005.

PRADO, Antônio Arnoni. 1922-Itinerário de uma falsa vanguarda: os dissidentes, a semana e o integralismo. São Paulo: Brasiliense, 1983

REIS, José Carlos. As identidades do Brasil: de Varnhagem a FHC. Rio de Janeiro: Ed. FGV, 1999.

SAES, Flávio Azevedo Marques de. Uma releitura de Raízes do Brasil, de Sérgio Buarque de Holanda. Territórios \& Fronteiras, Cuiabá, UFMT, v. 5, n. 2, 2004.

SANTOS, Luiz Antônio de Castro. O espírito da aldeia: orgulho ferido e vaidade intelectual em Gilberto Freyre. Novos Estudos CEBRAP. São Paulo, CEBRAP, n. 27, 1990

SCWHARCZ, Lilia Moritz. Nem preto nem branco, muito pelo contrário: cor e raça na intimidade. In: (Org.) História da vida privada no Brasil. São Paulo: $\overline{C o m p a n h i a}$ das Letras, 1998. v. 4

SILVA, Mozart Linhares da. Aquém e além da modernidade: aproximações e distanciamentos entre Sérgio Buarque de Holanda e Gilberto Freyre. Agora, Santa Cruz do Sul-SC, UNISC, v. 11, n. 1, 2005.

SOUZA, Jessé. Elias, Weber e a singularidade cultural brasileira. In: NEIBURG, Federico et al .Dossiê Norbert Elias. São Paulo: EDUSP, 1999a.

Max Weber, patrimonialismo e a formação cultural brasileira. In: COSTA, Sílvio (Org.) Concepcões e formação do Estado brasileiro. São Paulo: Anita Garibaldi, 1999b.

A ética protestante e a ideologia do atraso brasileiro. In: $\quad$ (Org.). O malandro e o protestante: a tese Ed. UNB, 1999c.

A modernização seletiva: uma reinterpretação do dilema brasileiro. Brasília: Ed. UNB, 2000.

VAINFAS, Ronaldo. Visão do Paraíso: biografia de uma idéia. In: MOTA, Lourenço Dantas (Org.) Introdução ao Brasil: um banquete nos trópicos. São Paulo: Ed. SENAC, 2002. v.2

VELOSO, Mariza; MADEIRA, Angélica. Leituras brasileiras: itinerários no pensamento social e na literatura. Rio de Janeiro: Paz e Terra, 1999.

WEBER, Max. Ensaios de sociologia. Rio de Janeiro: Zahar, 1974.

WEGNER, Robert. Os EUA e a fronteira na obra de Sérgio Buarque de Holanda. In: SOUZA, Jessé de (Org.). O malandro e o protestante: a tese weberiana e a singularidade cultural brasileira. Brasília: Ed. UNB, 1999.

. A conquista do Oeste: a fronteira na obra de Sérgio Buarque de Holanda. Belo Horizonte: Ed. UFMG, 2000. 


\section{AS RAÍZES E O FUTURO DO "HOMEM CORDIAL" SEGUNDO SÉRGIO BUARQUE DE HOLANDA}

Ricardo Luiz de Souza
THE ROOTS AND THE “CORDIAL MAN'S” UTURE ACCORDING TO SÉRGIO BUARQUE DE HOLANDA

Ricardo Luiz de Souza

This paper makes an analysis of do utilizado por Sérgio Buarque de the method used by Sérgio Buarque de Holanda e de seu conceito de Homem Holanda and of his concept of Cordial
Cordial, mostrando como ambos foram Man, showing how both were buil construídos a partir da tipologia weberiana starting from the weberian typology and e como esse conceito fundamentou a how the Cordial Man's concept based análise política do autor. Analisa a ques- the author's political analysis. It analyzes le concept de l'Homme Cordial a servi tão da identidade nacional na perspecti- the subject of the national identity in de base à l'analyse politique de l'auteur. va do autor, e assinala o processo de the author's perspective, and it marks La question de l'identite nationale est longo de sua obra.

\section{LES RACINES ET L'AVENIR DE BUARQUE DE HOLANDA}

Ricardo Luiz de Souza

Le texte présente l'analyse de la méthode utilisée par Sérgio Buarque de Holanda et de son concept d'Homme Cordial. Il montre de quelle manière ces le concept de l'Homme Cordial a serv présentée dans la perspective de l'auteur et on y montre le processus de reformulation dont une telle question a souffert tout au long de son œuvre.

Palavras-chave: identidade nacional, Keywords: national identity, modernity, Mots-CLÉs: identité nationale, modernité, modernidade, história. history.

Ricardo Luiz de Souza - Doutor em História pela Universidade Federal de Minas Gerais. Mestre em sociologia. Professor da Fundação Educacional Monsenhor Messias - UNIFEMM do Centro Universitário de Sete Lagoas. É autor de Identidade nacional e modernidade na historiografia brasileira: o diálogo entre Sílvio Romero, Euclides da Cunha, Câmara Cascudo e Gilberto Freyre. Belo Horizonte: Autêntica, 2007, e de mais de 40 artigos publicados em diversas revistas universitárias brasileiras. 